\title{
Identification of Eighteen Berberis Species as Alternate Hosts of Puccinia striiformis f. sp. tritici and Virulence Variation in the Pathogen Isolates from Natural Infection of Barberry Plants in China
}

\author{
Jie Zhao, Long Wang, Zhiyan Wang, Xianming Chen, Hongchang Zhang, Juanni Yao, \\ Gangming Zhan, Wen Chen, Lili Huang, and Zhensheng Kang
}

First, second, third, sixth, seventh, eighth, ninth, and tenth authors: Key State Laboratory of Crop Stress Biology for Arid Areas and College of Plant Protection, Northwest A\&F University, Yangling, Shaanxi 712100, China; fourth author: United States Department of Agriculture-Agricultural Research Service, Wheat Genetics, Quality, Physiology, and Disease Research Unit and Department of Plant Pathology, Washington State University, Pullman, WA 99164-6430; and fifth author: Key State Laboratory of Crop Stress Biology for Arid Areas and College of Life Sciences, Northwest A\&F University.

Accepted for publication 10 March 2013.

\begin{abstract}
Zhao, J., Wang, L., Wang, Z. Y., Chen, X. M., Zhang, H. C., Yao, J. N., Zhan, G. M., Chen, W., Huang, L. L., and Kang, Z. S. 2013. Identification of eighteen Berberis species as alternate hosts of Puccinia striiformis $\mathrm{f}$. sp. tritici and virulence variation in the pathogen isolates from natural infection of barberry plants in China. Phytopathology 103:927-934.

The wheat stripe rust pathogen (Puccinia striiformis f. sp. tritici) population in China has been reported to be a distinct genetic group with higher diversity than those in many other countries. Genetic recombination in the $P$. striiformis $\mathrm{f}$. sp. tritici population has been identified with molecular markers but whether sexual reproduction occurs in China is unknown. In this study, we surveyed barberry plants for infection by rust fungi in the stripe rust "hotspot" regions in Gansu, Sichuan, and Shaanxi provinces; collected barberry plants and inoculated plants of 20 Berberis spp. with germinated teliospores under controlled greenhouse conditions for susceptibility to $P$. striiformis f. sp. tritici; and tested $P$. striiformis f. sp. tritici isolates obtained from aecia on naturally infected barberry plants on the wheat genotypes used to differentiate Chinese $P$. striiformis f. sp. tritici races to determine virulence variations. Different Berberis spp. were widely distributed and most surveyed plants had pycnia and aecia of rust fungi throughout the surveyed regions. In total,

tested with teliospores of $P$. striiformis f. sp. tritici from wheat plants, 18 species were susceptible under greenhouse conditions. Among 3,703 aecia sampled from barberry plants of three species (Berberis shensiana, $B$. brachypoda, and B. soulieana) under natural infections in Gansu and Shaanxi provinces, four produced $P$. striiformis f. sp. tritici uredinia on susceptible wheat 'Mingxian 169'. Sequence of the internal transcribed spacer (ITS) regions of the four isolates from barberry shared $99 \%$ identity with the P. striiformis f. sp. tritici sequences in the National Center for Biotechnology Information database. The four isolates had virulence patterns different from all previously reported races collected from wheat plants. Furthermore, 82 single-uredinium isolates obtained from the four barberry isolates had high virulence diversity rates of 9.0 to $28.1 \%$, indicating that the diverse isolates were produced through sexual reproduction on barberry plants under natural conditions. In addition to P. striiformis f. sp. tritici, sequence analysis of polymerase chain reaction products of the ITS regions and inoculation tests on wheat identified $P$. graminis (the stem rust pathogen). Our results indicated that $P$. striiformis f. sp. tritici can infect some Berberis spp. under natural conditions, and the sexual cycle of the fungus may contribute to the diversity of $P$. striiformis f. sp. tritici in China.
\end{abstract} 28 Berberis spp. were identified during our study. From 20 Berberis spp.

Stripe rust, caused by the obligate biotrophic fungus Puccinia striiformis f. sp. tritici Erikss., is considered to be one of the most destructive diseases of wheat worldwide $(2,27)$. In China, epidemics of stripe rust have frequently caused huge yield losses in wheat-growing regions $(13,29)$. Use of resistant cultivars is a major approach for control of wheat stripe rust because of its low cost, effectiveness, and environmental friendliness. However, rapid virulence changes in the $P$. striiformis f. sp. tritici population have rendered many previously resistant cultivars susceptible, resulting in devastating epidemics $(1,14,29)$.

$P$. striiformis f. sp. tritici is known to be one of the most variable cereal rust pathogens in relation to virulence. Pathogen variability in virulence has been attributed to mutation and somatic hybridization based on previous studies of hyphal fusion $(6,10)$,

Corresponding author: Z. Kang; E-mail address: kangzs@nwsuaf.edu.cn

* The $\boldsymbol{e}$-Xtra logo stands for "electronic extra" and indicates that the online version contains two supplemental tables and one supplemental figure.

http://dx.doi.org/10.1094/PHYTO-09-12-0249-R

(c) 2013 The American Phytopathological Society
Additional keyword: pathotypes. heterokaryosis $(5,9,11,16)$, germ tube fusion $(19,23,36)$, and genetic recombination $(4,18,20)$. The function of sexual hybridization for virulence variation has been neglected because the sexual stage was presumed to be absent. Recently, barberry plants (Berberis spp.) were found to be infected by natural infection of the bluegrass stripe rust pathogen, $P$. pseudostriiformis (17), previously known as $P$. striiformis f. sp. poae, in Minnesota, and were infected following inoculation with $P$. striiformis f. sp. tritici teliospores under greenhouse conditions (8). In our laboratory, Zhao et al. (35) confirmed that some Berberis spp. could be infected by $P$. striiformis f. sp. tritici under controlled greenhouse conditions. The finding of alternate hosts for $P$. striiformis f. sp. tritici is critical for a better understanding of the pathogen lifecycle and mechanisms of virulence variation. Berberis spp. have been well known as alternate hosts for $P$. graminis $\mathrm{f}$. sp. tritici for a century (24); however, whether they can be infected by $P$. striiformis f. sp. tritici under natural conditions was not clear.

In China, $\approx 250$ Berberis spp. have been recorded, accounting for nearly $50 \%$ of the species recorded in the world. Most Berberis spp. are distributed in northwestern and southwestern China (22), including Gansu, Sichuan, Shaanxi, Guizhou, Yunnan, 
and Tibet provinces. In field surveys in 2010 to 2011, we found that a large number of barberry plants grew widely in the mountains or around wheat fields in Gansu, Sichuan, Shaanxi, Guizhou, and Yunnan provinces and that most barberry plants were infected by rust fungi in the intensively surveyed areas in Gansu, Shaanxi, and Sichuan provinces. These regions are considered "hotspots" of wheat stripe rust in China because $P$. striiformis f. sp. tritici can oversummer or overwinter (13,29). Among these regions, southern Gansu is particularly important because the pathogen is able to oversummer in the highlands (altitude: $2,500 \mathrm{~m}$ ) and overwinter in the lowlands (altitude: 1,000 m). Southern Gansu not only provides $P$. striiformis f. sp. tritici inoculum for infecting other regions but also serves as a major location for the pathogen to evolve. Most Chinese P. striiformis $\mathrm{f}$. sp. tritici races were first found in this region and, therefore, it has been considered to be a "center of origin" for Chinese $P$. striiformis f. sp. tritici races (1,12-14,29,31,32). Intensive studies using molecular markers identified genetic diversity for the $P$. striiformis f. sp. tritici population in China, especially the southern Gansu region $(18,20,25,30,33,37)$. Because of the relatively high diversity of the Chinese P. striiformis f. sp. tritici population compared with those of Europe and Australia, Mboup et al. (20) speculated that genetic recombination, possibly sexual recombination, occurs in the Chinese population. However, there was no study that provided direct evidence for sexual recombination in $P$. striiformis f. sp. tritici in any part of the world. Therefore, we have focused our study on the center of origin, southern Gansu, and major stripe rust epidemic regions such as Shaanxi and Sichuan to determine the roles of barberry plants in wheat stripe rust epidemics and pathogen variation.

The objectives of this study were to (i) determine distribution of and prevalence of infection by rust fungi on barberry plants through surveys, (ii) identify Berberis spp. for susceptibility to $P$. striiformis f. sp. tritici under controlled greenhouse conditions, and (iii) identify $P$. striiformis f. sp. tritici and determine virulence variation for $P$. striiformis $\mathrm{f}$. $\mathrm{sp}$. tritici isolates from naturally infected barberry plants.

\section{MATERIALS AND METHODS}

Field surveys for barberry plants, rusting barberry plants, and collection of barberry and rust fungal samples. Field surveys were conducted in Shaanxi, Gansu, Sichuan, Guizhou, and Yunnan provinces from May to October in 2010 and 2011. These provinces and locations were selected because they are stripe rust oversummering or overwintering regions (14) and most likely have barberry plants, based on the previous records (22). Because the major purpose of the barberry surveys was to find as many bushes and as many rust-fungus-infected bushes as possible, and also because barberry bushes often grow on mountain slopes and along stream banks, the surveyed area varied from location to location, ranging from $\approx 10$ to $30 \mathrm{~km}^{2}$. To cover as many areas as possible during each survey trip of 3 to 5 days by 5 to 7 people, a location was selected for survey based on geographic topology, proximity to agricultural fields (especially wheat fields), plantation, and accessibility, and there was a minimum of $10 \mathrm{~km}$ between two adjacent locations. At each location, the team members walked in different directions to cover an area of 500 to $1,000 \mathrm{~m}$. Locations, number of barberry plants, and number of rusting plants were recorded during the surveys. Pictures of plants were taken and leaves, flowers, berries, and young seedlings were collected for identification of Berberis spp. Seed from berries and young seedlings were used to grow plants in greenhouses for further identification of Berberis spp. and for inoculation experiments to determine their susceptibility to $P$. striiformis f. sp. tritici. Barberry leaves with aecia were collected in May and June 2010 and 2011 to determine Puccinia spp.

Identification of Berberis spp. for susceptibility to $\boldsymbol{P}$. striiformis f. sp. tritici. Seed or young plants of Berberis spp. collected from different provinces were planted or transplanted in pots filled with potting soil mixture and grown in a greenhouse. Plants with young leaves were used for inoculation with telia from wheat plants. Wheat (Triticum aestivum L.) leaves bearing telia of $P$. striiformis f. sp. tritici were collected from an experimental field in Yangling, Shaanxi in late May before the wheat crop was ma-

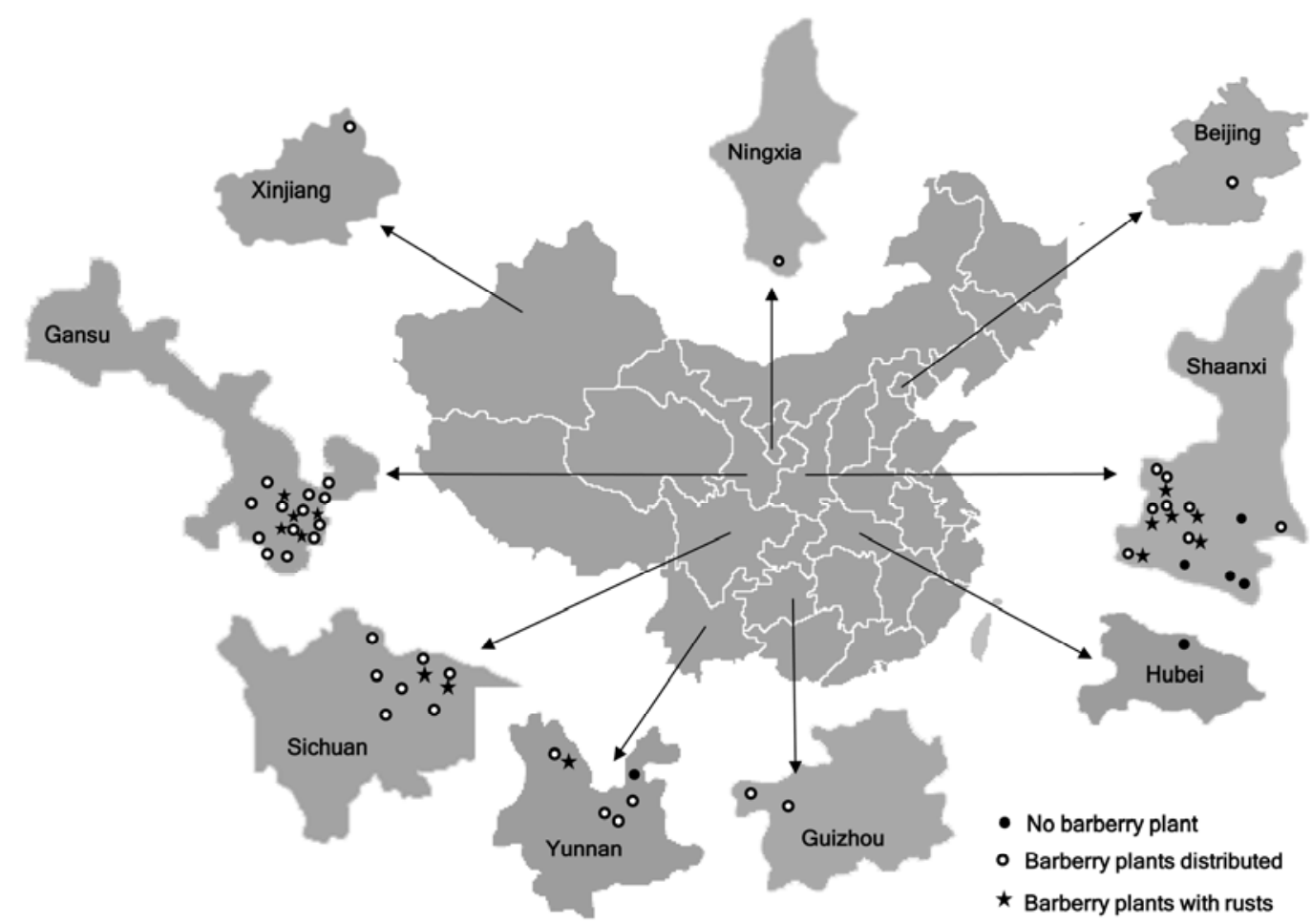

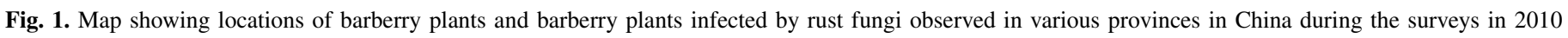
and 2011 . 
ture. The leaf samples were air dried at room temperatures for 2 to 3 days and then kept in a desiccator at $4{ }^{\circ} \mathrm{C}$ for later use.

Prior to inoculation, wheat leaves bearing telia of $P$. striiformis f. sp. tritici were soaked in distilled water at room temperature for $24 \mathrm{~h}$, rinsed with distilled water, and kept on $2 \%$ water agar (wt/vol) in a $25-\mathrm{cm}$-diameter petri dish. Teliospore germination on water agar in petri dishes was observed periodically under a light microscope. When teliospore germination was observed (usually $24 \mathrm{~h}$ after plating), leaf tissue was placed over barberry plants using a piece of wire mesh that was fixed on the top of plastic cylinder, and plants were kept for 3 to 4 days in a dew chamber with a cycle of $12 \mathrm{~h}$ of darkness at $12^{\circ} \mathrm{C}$ and $12 \mathrm{~h}$ of light at $16^{\circ} \mathrm{C}$. After incubation, the inoculated plants were moved to a growth chamber with the same diurnal light and temperature cycle. Plants were checked daily for symptoms and signs of rust fungi $\approx 7$ days after removal from the dew chamber.

To confirm that the aecia produced on barberry leaves resulted from the artificial inoculation to be $P$. striiformis f. sp. tritici, leaves of Berberis shensiana with mature aecia were placed onto a glass slide on filter paper saturated with sterilized water in a petri dish for $6 \mathrm{~h}$ to trigger the release of aeciospores. Aeciospores on the glass slide were collected and made into an aeciospore suspension with a drop of sterilized water. The aeciospore suspension was inoculated onto first leaves of wheat 'Mingxian 169', which is susceptible to all $P$. striiformis $\mathrm{f}$. sp. tritici races identified in China thus far (1). The inoculated wheat plants were main-

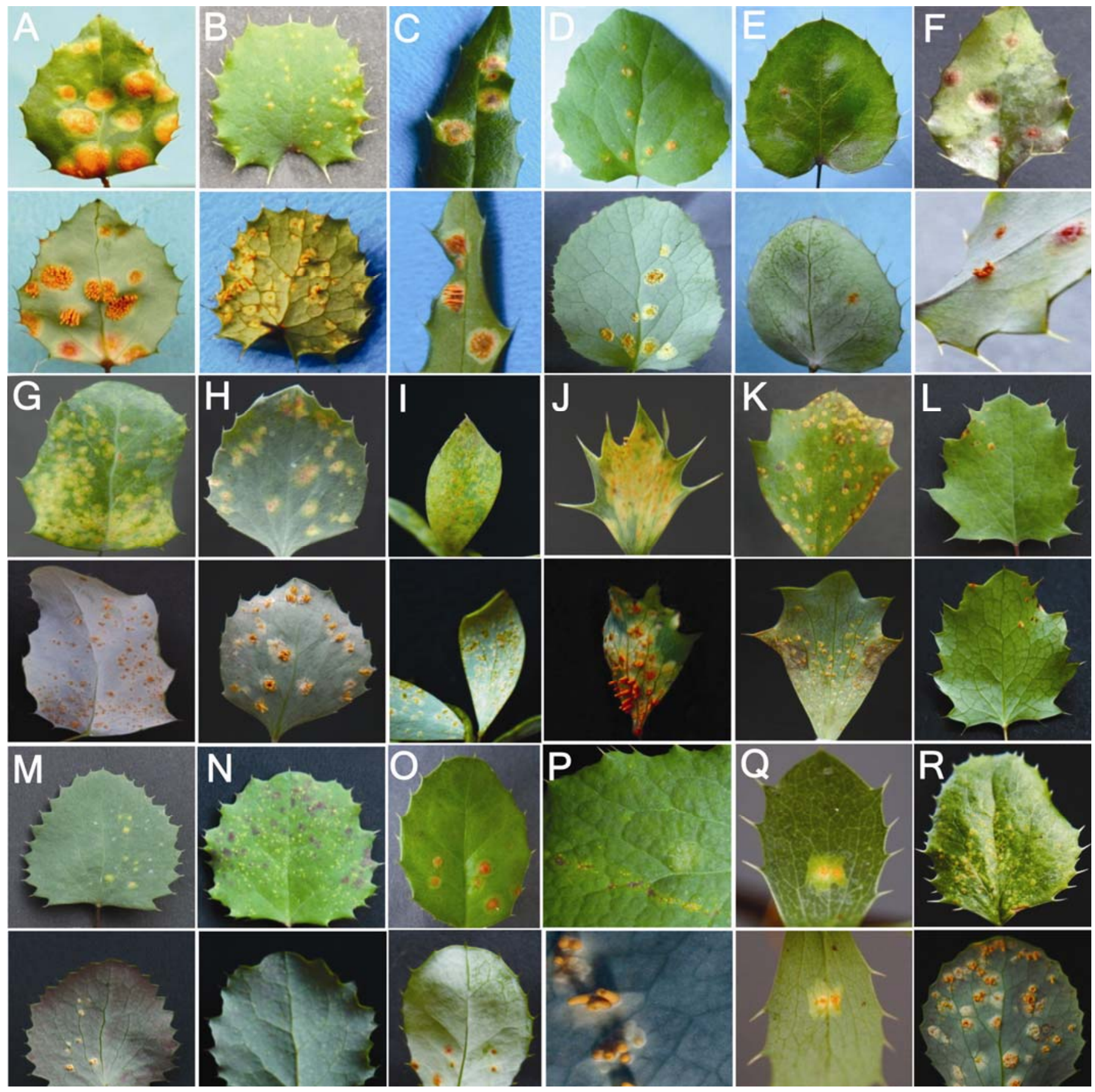

Fig. 2. Eighteen Berberis spp. identified to be susceptible to Puccinia striiformis f. sp. tritici after inoculation with germinated teliospores under controlled greenhouse conditions, showing pycnia (first, third, and fifth rows) on the upper surface of the leaves and aecia (second, fourth, and sixth rows) on the back of the leaves; photos taken at 9 to 11 and 16 to 20 days after inoculation, respectively. A, Berberis atrocarpa; B, B. stenostachya; C, B. soulieana; D, B. shensiana; E, B. wangii; $\mathbf{F}$, B. phanera; $\mathbf{G}$, B. davidii; $\mathbf{H}$, B. poiretii; $\mathbf{I}$, B. aggregata var. integrifolia; $\mathbf{J}$, B. potaninii; $\mathbf{K}$, B. jamesiana; L, B. ferdinandi-coburgii; $\mathbf{M}$, B. brachypoda; $\mathbf{N}$, B. circumserrata $; \mathbf{O}$, B. platyphylla; $\mathbf{P}$, B. dasystachya $\mathbf{Q}, B$. aggregata; and $\mathbf{R}, B$. guizhouensis. 
tained for $24 \mathrm{~h}$ at $10^{\circ} \mathrm{C}$ in a dew chamber without light. After incubation, plants were kept in a growth chamber at $16^{\circ} \mathrm{C}$ with a cycle of $16 \mathrm{~h}$ of light and $8 \mathrm{~h}$ of darkness. Uredinia produced on wheat plants were observed 15 to 20 days after inoculation, when the disease was fully developed.

Inoculation of wheat plants with aecial samples collected from naturally infected barberry plants. Individual aecia were excised from infected barberry leaves and kept on a watersaturated filter paper in a petri dish for 4 to $6 \mathrm{~h}$ to release aeciospores. The aeciospore suspension was used to inoculate seedlings of Mingxian 169 wheat. The inoculated wheat plants were incubated in a dew chamber for $24 \mathrm{~h}$ at $10^{\circ} \mathrm{C}$ without light, then kept in a growth chamber at $16^{\circ} \mathrm{C}$ with a cycle of $16 \mathrm{~h}$ of light and $8 \mathrm{~h}$ of darkness. Uredinial sporulation was observed 15 to 20 days after inoculation.

Polymerase chain reaction amplification and sequence analysis of the internal transcribed spacer region. DNA was extracted from wheat leaf segments containing uredinia produced on Mingxian 169 inoculated with aeciospores from a single aecium from natural infection of barberry plants from Gansu and Shaanxi provinces. A pair of $P$. striiformis $\mathrm{f}$. sp. tritici-specific primers, PSF( $5^{\prime}$-GGATGTTGAGTGCTGCTGTAA-3')/PSR(5'TTGAGGTCTTAAGGTTAAAATTG-3'), developed in our laboratory (34), and a pair of primers, Puccina-IT3 (5'-ACATCG ATGAAGAACACAGT-3') and internal transcribed spacer (ITS) 4 (5'-TCCTCCGCTTATTGATATGC-3'), developed by Drs. Meinan Wang and Xianming Chen at the United States Department of Agriculture-Agricultural Research Service and Washington State University were used to detect $P$. striiformis f. sp. tritici and P. graminis f. sp. tritici. Polymerase chain reaction (PCR) products were sequenced by Beijing Aoke Dingsheng Bio-Tech Ltd. Sequence comparison of the ITS regions were performed at the National Center for Biotechnology Information (NCBI) website (http://www.ncbi.nlm.nih.gov/). Nucleotide sequences were submitted to the GenBank (accession numbers KC677563 to KC677573 for P. graminis and KC677574 to KC677577 for $P$. striiformis f. sp. tritici).

Identification of virulence patterns of $\boldsymbol{P}$. striiformis $\mathbf{f}$. sp. tritici isolates from naturally infected barberry plants. Urediniospores of the P. striiformis $\mathrm{f}$. sp. tritici isolates derived from individual aecia of naturally infected barberry species were inoculated onto the set of 19 wheat genotypes used to differentiate Chinese $P$. striiformis f. sp. tritici races using the method described by Chen et al. (1). Infection type (IT) data were recorded
15 to 20 days after inoculation based on a 0 -to- 9 scale as described by Line and Qayoum (15).

A single-aecium (SA) isolate was established by harvesting urediniospores from leaves of Mingxian 169 inoculated with aeciospores from a single aecium that consisted of 3 to $>10$ aecial cups on a naturally infected barberry leaf. In order to confirm that the urediniospores of an SA isolate were from the aecium through sexual reproduction on the barberry plants, single-uredinium (SU) isolates were obtained from the $\mathrm{SA}$ isolate by transferring urediniospores from a single uredinium on sporulating Mingxian 169 plants inoculated with aeciospores of an aecium onto new plants of Mingxian 169 using a metal pin with Vaseline jelly around its tip (13). The reisolation was done at the early sporulation stage $(\approx 13$ to 15 days after inoculation) when uredinial pustules could be clearly separated. Only one uredinium was picked from a clearly separate uredinial pustule that was presumably produced by a single aeciospore. Inoculated wheat plants were covered using a transparent plastic cylinder to avoid cross contamination. The set of differential genotypes used to determine virulence patterns of SU isolates, inoculation, growth conditions, and data recording were the same as described above.

\section{RESULTS}

Distribution and identification of Berberis spp. and their plants infected by rust fungi. Barberry plants were found to be widespread in the surveyed areas of Shaanxi, Gansu, Sichuan, Yunnan, and Guizhou provinces (Fig. 1; Supplemental Table 1). Barberry plants were found to grow along streams, mountain slopes, and edges of fields grown with wheat or other crops. In all, $\approx 2,000$ barberry bushes were found in western Shaanxi Province and $>3,000$ in southern Gansu Province during our field surveys. Sometimes, $>50$ bushes were found within an area of $10,000 \mathrm{~m}^{2}$. Depending upon species and locations, the bushes ranged from one or two stems of a half-meter to $\approx 10 \mathrm{~m}$ in height with a canopy of $10 \mathrm{~m}$ in diameter. In total, 28 Berberis spp. were recognized during this study, and the distributions of 20 of them used in the greenhouse tests are listed in Table 1.

Most barberry bushes were found to be infected by rust fungi. Fully developed aecia were found from early May to late June depending upon region and elevation. Incidence of rust ranged from hard-to-find to almost $100 \%$. Infected leaves had 1 to $>10$ aecia and aecia sizes were 1 to $20 \mathrm{~mm}$ in diameter or length. Fresh, mature aecia were yellow to red, with varying numbers and

TABLE 1. Berberis spp. tested for susceptibility to Puccinia striiformis f. sp. tritici under controlled greenhouse conditions and their geographic locations

\begin{tabular}{llll}
\hline Number $^{\mathrm{a}}$ & ID number & \multicolumn{1}{c}{ Berberis spp. } & \multicolumn{1}{c}{ Collection location } \\
\hline 1 & BPI001 & Berberis aggregata & Jianshan village, Qishou town, Gansu \\
2 & BPI002 & B. brachypoda & Xujiadian, Zaojiao town, Gansu \\
3 & BPI003 & B. potaninii & Caoliangyi village, Honghuapu town, Feng county, Shaanxi \\
4 & BPI004 & B. soulieana & Diaogou village, Jiangluo town, Hui county, Gansu \\
5 & BPI005 & B. dasystachya & Huoditang town, Ningshan county, Ankang, Shaanxi \\
6 & BPI006 & B. shensiana & Yingge town, Taibai county, Baoji, Shaanxi \\
7 & BPI007 & B. atrocarpa & Youai town, Pi county, Sichuan \\
8 & BPI008 & B. ferdinandi-coburgii & Xiaoqing village, Shilin town, Kunmiing, Yunnan \\
9 & BPI009 & B. phanera & Xiaoshao village, Shizong county, Qujing, Kunming, Yunnan \\
10 & BPI010 & B. aggregata var. integrifolia & Botanical Garden, Kunming, Yunnan \\
11 & BPI011 & B. davidii & Xishan Mountain, Kunming, Yunnan \\
12 & BPI012 & B. stenostachya & Lingguan village, Yangdian town, Liangdang county, Longnan, Gansu \\
13 & BPI013 & B. wangii & Xishan Mountain, Kunming, Yunnan \\
14 & BPI014 & B. circumserrata & Caiyuan village, Xinjie town, Baoji, Shaanxi \\
15 & BPI015 & B. poiretii & Botanical Garden, Beijing \\
16 & BPI016 & B. guizhouensis & Haiga village, Dayi town, Hezhang county, Bijie, Guizhou \\
17 & BPI017 & B. platyphylla & Botanical Garden, Kunming, Yunnan \\
18 & BPI018 & B. jamesiana & Botanical Garden, Kunming, Yunnan \\
19 & BPI019 & B. vernalis & Xishan Mountain, Kunming, Yunnan \\
20 & BPI020 & B. coryi & $+/+$ \\
\hline
\end{tabular}

${ }^{\text {a }}$ Species number 1-18 were susceptible to $P$. striiformis f. sp. tritici in the greenhouse tests.

b Presence (+) and absence (-) of pycnia or aecia. 
lengths of cluster-cups. It was not possible to identify Puccinia spp. based on the morphology of aecia on barberry plants during the field surveys.

Berberis spp. susceptible to $\boldsymbol{P}$. striiformis f. sp. tritici. Of the 20 Berberis spp. inoculated with telia from wheat plants under controlled greenhouse conditions, 18 species produced pycnia at $\approx 9$ days and aecia at 17 days after inoculation (Table 1; Fig. 2). No obvious differences in the latent period (days between inoculation and pycnial or aecial formation) were observed among the species. However, the number and size of pycnia or aecia and aecial cluster-cups were different among the Berberis spp., indicating different levels of susceptibility to $P$. striiformis $\mathrm{f}$. sp. tritici. A quantitative comparison of the susceptibility among the species was not possible, because the experiments were conducted over time in a qualitative manner. However, based on the number and size of pycnia and aecia and number of leaves with pycnia and aecia, B. atrocarpa, B. soulieana, B. poiretii, $B$. potaninii, B. dasystachya, and B. guizhouensis appeared to be more susceptible to $P$. striiformis f. sp. tritici than the other species. Aeciospores produced on leaves of $B$. shensiana, which appeared to be relatively easy to grow under the greenhouse conditions, after inoculation of $P$. striiformis $\mathrm{f}$. sp. tritici teliospores were used to inoculate Mingxian 169 wheat, generating uredinia typical of $P$. striiformis $\mathrm{f}$. sp. tritici 11 days after inoculation. The results indicated that the 18 Berberis spp. were susceptible to P. striiformis f. sp. tritici under the test conditions (Table 1). Two species, $B$. vernalis, and B. coryi, did not produce any visible symptoms or signs in the three repeated experiments and, therefore, were not considered hosts of $P$. striiformis f. sp. tritici.

$P$. striiformis f. $\mathbf{s p}$. tritici isolates obtained from naturally infected barberry plants. In the surveys during May to June
2011, five barberry species (B. shensiana, B. soulieana, B. brachypoda, $B$. potaninii, and $B$. aggregate) were found to have pycnia or aecia in Gansu and Shaanxi provinces. In total, 3,703 individual aecia sampled from the five Berberis spp. (Table 2) were used to inoculate seedlings of Mingxian 169. Only four aeciatwo from $B$. brachypoda, one from $B$. shensiana, and one from $B$. soulieana-produced uredinia typical of $P$. striiformis on Mingxian 169 . To distinguish from $P$. striiformis f. sp. tritici urediniospore isolates originally from wheat, the urediniospore isolates of P. striiformis f. sp. tritici obtained by inoculating Mingxian 169 with aeciospores of individual aecia from naturally infected barberry plants were referred as to SA isolates, designated as B2011-1, B2011-2, B2011-3, and B2011-4 (Table 2; Fig. 3). Isolates B2011-1 and B2011-2 were obtained from two aecia among 1,519 aecia picked from B. brachypoda in Gansu Province, B2011-3 from one aecium among 410 aecia from $B$. shensiana in Shaanxi Province, and B2011-4 from one aecium among 384 aecia from $B$. soulieana from Gansu. However, aeciospores from the 742 aecia from $B$. potaninii and the 648 aecia from $B$. aggregata failed to produce any uredinia on Mingxian 169 (Table 2). In addition, six aecia from $B$. brachypoda, three from $B$. potaninii, and two from $B$. aggregata produced uredinia of $P$. graminis on Mingxian 169 (Table 2). Among the 3,703 aecia from the five Berberis spp., 2,209 produced IT 0 (no visible symptoms or signs) and 1,463 produced IT 1 (small necrotic flecks) and IT 2 (necrotic blotches). Although the aecia that produced IT 0 were either highly avirulent or, possibly, failed inoculation, those producing IT 1 or 2 were clearly avirulent or nonpathogenic to Mingxian 169 wheat and unlikely to be $P$. striiformis f. sp. tritici. The results indicated a very low frequency $(0.11 \%)$ of $P$. striiformis f. sp. tritici among the rust fungi infecting the barberry plants.

TABLE 2. Numbers of aecia collected from naturally infected Berberis spp. in Gansu and Shaanxi provinces in May and June 2011 and numbers of aecia which produced uredinia (susceptible infection types [ITs] 8 to 9) of Puccinia striiformis f. sp. tritici or P. graminis f. sp. tritici, and resistant reactions (ITs 0 to 2 ) tested on 'Mingxian 169' wheat

\begin{tabular}{|c|c|c|c|c|c|}
\hline \multirow[b]{2}{*}{ Berberis spp. } & \multirow[b]{2}{*}{ Number of aecia } & \multicolumn{2}{|c|}{ Susceptible (ITs 8-9) } & \multicolumn{2}{|c|}{ Resistant } \\
\hline & & P. striiformis f. sp. tritici & P. graminis f. sp. tritici & Chlorosis/necrosis (IT 1-2) & Noninfection (IT 0) \\
\hline Berberis brachypoda & 1,519 & $2^{\mathrm{a}}$ & 6 & 1,032 & 479 \\
\hline B. shensiana & 410 & $1^{\mathrm{b}}$ & 0 & 374 & 35 \\
\hline B. soulieana & 384 & $1^{\mathrm{c}}$ & 0 & 16 & 367 \\
\hline B. potaninii & 742 & 0 & 3 & 28 & 711 \\
\hline B. aggregata & 648 & 0 & 2 & 13 & 633 \\
\hline
\end{tabular}

a Two uredinial isolates obtained from B. brachypoda were named B2011-1 and B2011-2.

b One uredinial isolate obtained from B. shensiana was named B2011-3.

c One uredinial isolate obtained from B. soulieana was named 2011-4.

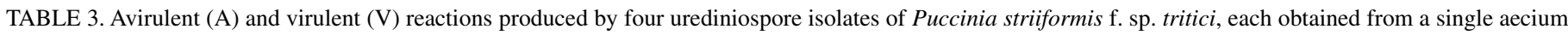

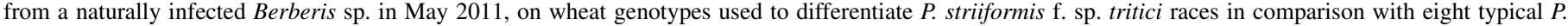
striiformis f. sp. tritici races originally from wheat (Triticum aestivum)

\begin{tabular}{|c|c|c|c|c|c|c|c|c|c|c|c|c|c|c|c|c|c|c|c|c|}
\hline \multirow[b]{2}{*}{ Isolate, race $^{\mathrm{a}}$} & \multirow[b]{2}{*}{ Origin of isolate } & \multicolumn{19}{|c|}{ Reactions on wheat differential genotypes ${ }^{b}$} \\
\hline & & 1 & 2 & 3 & 4 & 5 & 6 & 7 & 8 & 9 & 10 & 11 & 12 & 13 & 14 & 15 & 16 & 17 & 18 & 19 \\
\hline B2011-1 & Berberis brachypoda & A & $\mathrm{V}$ & A & $\mathrm{A}$ & V & $\mathrm{V}$ & A & $\mathrm{V}$ & A & VA & V & $\mathrm{A}$ & $\mathrm{A}$ & V & $\mathrm{A}$ & $\mathrm{A}$ & $\mathrm{A}$ & $\mathrm{A}$ & A \\
\hline B2011-2 & B. brachypoda & A & V & A & V & V & A & A & $\mathrm{V}$ & A & A & V & A & $\mathrm{A}$ & A & $\mathrm{A}$ & $\mathrm{A}$ & $\mathrm{A}$ & $\mathrm{A}$ & A \\
\hline B2011-3 & B. shensiana & A & V & $\mathrm{A}$ & $\mathrm{V}$ & V & A & $\mathrm{V}$ & $\mathrm{V}$ & A & AV & V & A & $\mathrm{A}$ & $\mathrm{A}$ & A & $\mathrm{A}$ & $\mathrm{A}$ & A & A \\
\hline B2011-4 & B. soulieana & $\mathrm{A}$ & V & $\mathrm{A}$ & $\mathrm{V}$ & V & V & A & $\mathrm{V}$ & A & $\mathrm{A}$ & A & A & $\mathrm{A}$ & $\mathrm{V}$ & A & $\mathrm{V}$ & $\mathrm{A}$ & $\mathrm{A}$ & A \\
\hline CYR33 & T. aestivum & AV & $\mathrm{V}$ & V & V & VA & V & V & V & V & V & V & $\mathrm{V}$ & $\mathrm{V}$ & $\mathrm{V}$ & $\mathrm{A}$ & $\mathrm{V}$ & $\mathrm{A}$ & $\mathrm{A}$ & A \\
\hline CYR32 & T. aestivum & $\mathrm{V}$ & V & V & V & $\mathrm{V}$ & V & V & $\mathrm{V}$ & V & V & V & V & V & V & $\mathrm{A}$ & $\mathrm{V}$ & $\mathrm{V}$ & $\mathrm{A}$ & A \\
\hline CYR31 & T. aestivum & V & $\mathrm{V}$ & $\mathrm{V}$ & V & V & V & V & V & V & A & V & $\mathrm{V}$ & $\mathrm{A}$ & $\mathrm{V}$ & $\mathrm{A}$ & $\mathrm{V}$ & $\mathrm{V}$ & $\mathrm{A}$ & A \\
\hline CYR30 & T. aestivum & V & V & V & V & V & V & V & V & V & A & V & $\mathrm{V}$ & $\mathrm{A}$ & $\mathrm{A}$ & $\mathrm{A}$ & $\mathrm{V}$ & $\mathrm{V}$ & $\mathrm{A}$ & A \\
\hline CYR29 & T. aestivum & V & $\mathrm{V}$ & V & V & V & V & V & V & V & A & V & $\mathrm{V}$ & $\mathrm{A}$ & A & $\mathrm{A}$ & $\mathrm{V}$ & $\mathrm{A}$ & $\mathrm{A}$ & A \\
\hline CYR28 & T. aestivum & V & V & V & V & V & V & V & V & V & A & V & A & $\mathrm{A}$ & $\mathrm{A}$ & $\mathrm{A}$ & V & $\mathrm{A}$ & $\mathrm{A}$ & A \\
\hline CYR23 & T. aestivum & V & $\mathrm{V}$ & V & V & A & V & V & $\mathrm{V}$ & V & A & V & $\mathrm{A}$ & $\mathrm{A}$ & $\mathrm{A}$ & $\mathrm{A}$ & $\mathrm{A}$ & $\mathrm{A}$ & $\mathrm{A}$ & A \\
\hline CYR17 & T. aestivum & VA & V & A & VA & A & VA & V & A & A & A & AV & $\mathrm{A}$ & $\mathrm{A}$ & $\mathrm{A}$ & $\mathrm{A}$ & $\mathrm{A}$ & $\mathrm{A}$ & $\mathrm{A}$ & $\mathrm{A}$ \\
\hline
\end{tabular}

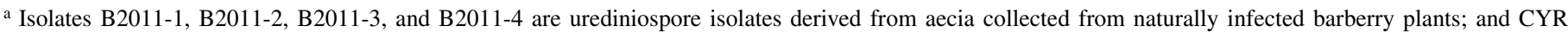
indicates races of Chinese yellow rust originally collected from wheat.

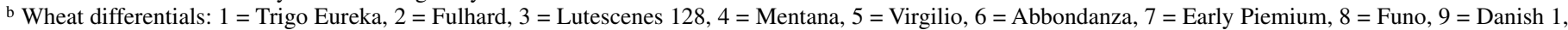
$10=$ Jubilejina $2,11=$ Fengchan $3,12=$ Lovrin $13,13=$ Kangyin $655,14=$ Suwon $11,15=$ Zhong $4,16=$ Lovrin $10,17=$ Hybrid $46,18=$ T. spelta ablum, $19=$ Guinong $22 . \mathrm{A}=$ avirulence (infection types 0 to 6 ), $\mathrm{V}=$ virulence (infection types 7 to 9 ), and AV/VA = mixed infection types. 
This may suggest that barberry plants play a minor role in wheat stripe rust in the surveyed areas.

PCR amplifications of urediniospore DNA from the four $P$. striiformis f. sp. tritici SA isolates from the three Berberis spp. produced the same size amplicons as $P$. striiformis $\mathrm{f}$. sp. tritici race CYR32, a predominant race used as a positive control. DNA sequence analysis of the ITS region indicated that the four isolates shared $99 \%$ identity with $P$. striiformis f. sp. tritici sequences (FJ224378, FJ224376, EU924747, GU382671, and GU382673) in the NCBI database. The results confirmed that the four SA isolates from B. shenensis, B. soulieana, and B. brachypoda were $P$. striiformis f. sp. tritici.

Virulence patterns of the $\mathrm{SA}$ isolates and their derived SU isolates. Virulence patterns of the four $P$. striiformis $\mathrm{f}$. sp. tritici SA isolates and eight typical $P$. striiformis f. sp. tritici races (CYR33, CYR32, CYR31, CYR30, CYR29, CYR28, CYR23, and CYR17) collected from wheat fields in Gansu (Q. Z. Jia, personal communication) and Shaanxi (B. T. Wang, personal communication) provinces in 2010 to 2011 for comparison are shown in Table 3. The four P. striiformis f. sp. tritici SA isolates had virulence patterns different from each other and also from the eight $P$. striiformis f. sp. tritici races from wheat fields (Table 3). Moreover, the virulence patterns of the four SA isolates were also different from all previously reported $P$. striiformis f. sp. tritici races. The virulence data ruled out the possibility that the four SA isolates could be from contaminations of $P$. striiformis f. sp. tritici isolates from wheat fields and further confirmed that they were produced sexually from $P$. striiformis f. sp. tritici-infected barberry plants under natural conditions.

To further confirm that the four SA isolates were produced through a sexual cycle on barberry plants, 82 SU isolates (41, 7, 7, and 27 from B2011-1, B2011-2, B2011-3, and B2011-4, respectively) were obtained by $\mathrm{SU}$ isolation from the uredinia produced on wheat plants inoculated with aeciospores of the SA isolates. Remarkable variation in virulence patterns were observed among the SU isolates from each SA isolate (Supplemental Table 2). Virulence diversity rates were $26.1 \%$ for SA isolate B2011-1 and its SU isolates, 9.0\% for B2011-2, 27.8\% for B2011-3, and 28.1\% for B2011-4. The results showed that the SA isolates originally from aecia on naturally infected barberry plants consisted of diverse virulence patterns, produced by sexual reproduction on the barberry plants.

\section{DISCUSSION}

In this study, 28 Berberis spp. were recognized, and some of the species grow widely in the center of origin for $P$. striiformis $\mathrm{f}$. sp. tritici races and hotspots of stripe rust epidemics in China.
Among the species, 18 were susceptible under controlled inoculation conditions and, therefore, could be alternate hosts for $P$. striiformis f. sp. tritici. Four $P$. striiformis f. sp. tritici isolates were obtained from aecia collected from naturally infected barberry plants. Virulence tests of these isolates and their derived progeny isolates confirmed that these isolates were produced from a sexual cycle that occurred on barberry plants. Together, these results indicate that a large number of Berberis spp. may be able to serve as alternate hosts for $P$. striiformis $\mathrm{f}$. sp. tritici because they were found to be susceptible in artificial inoculation tests under controlled greenhouse conditions. This study provided the first direct evidence that sexual reproduction of $P$. striiformis f. sp. tritici exists in China, which was speculated by Mboup et al. (20) based on molecular marker analysis of the Chinese P. striiformis f. sp. tritici population from wheat fields.

Barberry plants grow widely in China, especially in northwestern regions such as Gansu and Shaanxi provinces, where stripe rust epidemics occur most frequently. In our surveys in 2010 and 2011, barberry species were found from the lowlands to the highlands at different altitudes, ranging from hundreds to thousands meters. Barberry bushes in high densities were found in many surveyed sites. The large number of barberry bushes and their proximity to wheat fields provide good connections for $P$. striiformis f. sp. tritici to move between the asexual-cycle hosts and sexual-cycle hosts. Abundant aecia were observed on leaves of $B$. brachypoda, $B$. soulieana, $B$. shensiana, B. potaninii, and $B$. aggregata in Gansu, Shaanxi, and Sichuan provinces, where $P$. striiformis f. sp. tritici can oversummer or overwinter and provide inoculum for spreading to the eastern regions of China $(1,29)$.

In this study, only 4 aecia were found to be $P$. striiformis $\mathrm{f}$. sp. tritici among 3,703 aecia from barberry plants, indicating a very low percentage $(\approx 0.1 \%)$ of $P$. striiformis $\mathrm{f}$. sp. tritici on barberry plants. This result may indicate a low infection rate of barberry plants by $P$. striiformis $\mathrm{f}$. sp. tritici under natural conditions, and could explain why no obvious connection has been found between stripe rust of wheat and barberry, in contrast to stem rust (26). The low P. striiformis f. sp. tritici infection on barberry plants might be caused by the relatively low level of stripe rust in wheat fields in the surveyed regions in 2010 and 2011. Because weather conditions may affect $P$. striiformis f. sp. tritici infection on barberry plants and variation in infection rates is expected from year to year, annual surveys of barberry are needed to determine $P$. striiformis $\mathrm{f}$. sp. tritici infection on barberry plants. Even though we identified a large number of virulence patterns or races from the SA and their derived SU isolates from barberry plants, none of the patterns have been identified in $P$. striiformis $\mathrm{f}$. $\mathrm{sp}$. tritici samples from wheat fields. This could be due to the selec-

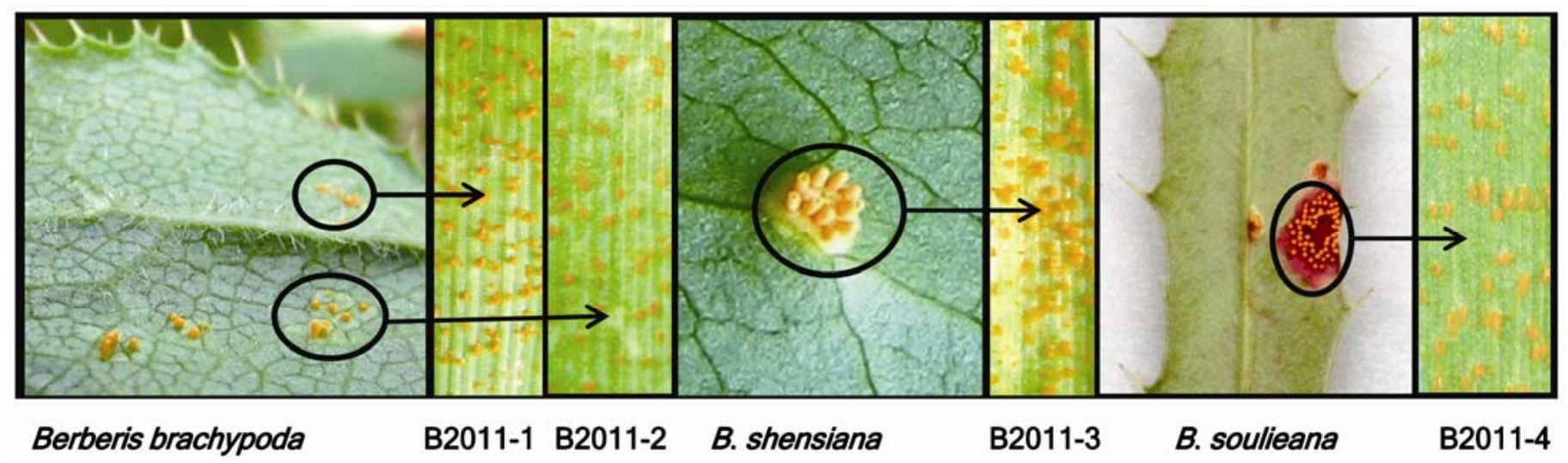

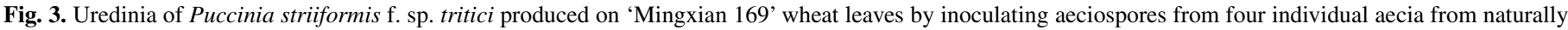

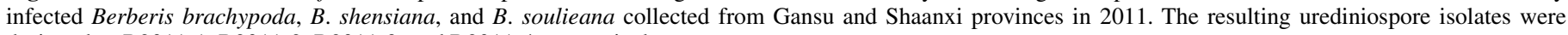
designed as B2011-1, B2011-2, B2011-3, and B2011-4, respectively. 
tion of resistance in wheat cultivars. However, further studies are needed to determine gene exchange between the $P$. striiformis $\mathrm{f}$. sp. tritici populations on barberry and wheat.

In addition to $P$. striiformis $\mathrm{f}$. sp. tritici, we also isolated $P$. graminis from barberry plants. Berberis spp. are well known as the alternate hosts for $P$. graminis $(24,26)$. The frequency of $P$. graminis f. sp. tritici was also low. This could be caused by the low temperatures we used as optimal for $P$. striiformis f. sp. tritici infection but not for $P$. graminis f. sp. tritici, because the major objective of this study was to determine the relationship of barberry to stripe rust. Also, because of the objective focused on stripe rust, Mingxian 169 wheat, which is considered universally susceptible to $P$. striiformis f. sp. tritici, may be resistant to some races of $P$. graminis f. sp. tritici and also may be a nonhost for other formae speciales of $P$. graminis. Further studies using wheat genotypes universally susceptible to $P$. graminis $\mathrm{f}$. $\mathrm{sp}$. tritici and other grasses, with temperatures optimal for $P$. graminis f. sp. tritici and other Puccinia spp., together with molecular markers and sequencing, are needed to sort out rust fungal species on barberry plants and to determine the importance of barberry to stem rust in China. In addition to $P$. striiformis f. sp. tritici and $P$. graminis $\mathrm{f}$. $\mathrm{sp}$. tritici found on barberry plants in the present study, we speculate that other formae speciales of $P$. striiformis and $P$. graminis and also other Puccinia spp. may infect barberry plants in China, because $99 \%$ of the tested 3,703 aecia produced incompatible (IT 0-2) reaction on Mingxian 169. Although it is possible that some of the infections might not be successful and some aecia might be $P$. striiformis or $P$. graminis but avirulent on Mingxian 169, other Puccinia spp., including >30 Puccinia spp. such as $P$. brachypodii (21), $P$. poa-nemoralis, $P$. pygmaea, $P$. montanensis, and $P$. brachypodii-phoenicoidis (3), and $P$. arrhenatheri (28), have been reported to infect Berberis spp. From this standpoint, Berberis spp. may play an important role in the evolution of Puccinia spp. A more thorough study of Puccinia spp. on various Berberis spp. should be helpful for a better understanding of plant-pathogen interactions involving different pathogens and hosts.

In the present study, virulence tests of the four $P$. striiformis $\mathrm{f}$. sp. tritici SA isolates (B2011-1, B2011-2, B2011-3, and B2011-4) and their derived SU isolates revealed a large number of virulence patterns different from all known Chinese P. striiformis f. sp. tritici races. This is typical for a sexually reproducing population and excludes the possibility of the successive SU isolates from contamination and, therefore, provides evidence of barberry infection by $P$. striiformis f. sp. tritici under natural conditions. Although the results provide evidence for natural infection of barberry by $P$. striiformis $\mathrm{f}$. sp. tritici, the present study did not provide strong evidence for a close relationship between the sexual population on barberry and the population on wheat crops, which may be due to the very low frequency of $P$. striiformis f. sp. tritici infection on barberry plants observed in this study. Further studies are needed to determine whether $P$. striiformis f. sp. tritici infection frequencies higher than the rate observed in this study can occur on barberry plants. $P$. striiformis f. sp. tritici can oversummer and overwinter on wheat crops and some grass species in the stripe rust epidemic regions in which we surveyed barberry plants in the present study; therefore, it is clear that $P$. striiformis f. sp. tritici on barberry plants rarely plays a role in initiating stripe rust on wheat crops. However, the sexual reproduction of $P$. striiformis $\mathrm{f}$. sp. tritici on barberry plants may generate unique races which could damage wheat crops, even at a low frequency of events. For the purpose of stripe rust management, especially for breeding for resistant cultivars, use of race nonspecific resistance should be a high priority, no matter whether barberry plays an important role in initiating annual disease development or generating new virulent races.

In addition to the large number of Berberis spp. and abundant plants found in western and southwestern China, a small number of Berberis spp. (22) and a relatively small number of plants have been recorded in the eastern China, including Hubei, Henan, and Anhui provinces. Studies in these regions are needed to determine whether these species are naturally infected by $P$. striiformis f. sp. tritici and, if so, whether the barberry plants provide initial inoculum for infecting wheat crops in these regions where $P$. striiformis f. sp. tritici inoculum usually come from other regions.

Although we found $P$. striiformis f. sp. tritici on barberry plants, it is still too early to make recommendations regarding whether barberry plants should be eradicated because the present study indicated a low rate of infection by $P$. striiformis f. sp. tritici. Unlike the essential role of barberry plants for stem rust epidemics in the U.S. Pacific Northwest $(7,24)$, P. striiformis f. sp. tritici does not rely on barberry for initiating stripe rust epidemics because the pathogen can survive and reproduce as the uredinial stage on spring and winter wheat crops, volunteer wheat plants, and other grasses. However, barberry plants may preserve unique pathotypes that cannot infect wheat cultivars and generate new pathotypes with different combinations of virulences. Studies are also needed to determine the maximum distance aeciospores can travel without losing viability. Such information is needed to develop stripe rust control strategies, including management of alternate hosts. Nevertheless, removing barberry plants on edges of wheat fields or spraying them with fungicides may be a good idea and feasible approach for minimizing the role of barberry in the disease epidemics and variability generation.

\section{ACKNOWLEDGMENTS}

This study was supported by National Key Basic Research Program of China (2013CB127700), International Science \& Technology Cooperation Program of China (2011DFG32990), National Natural Science Foundation of China (31271986), Modern Agro-industry Technology Research System in China (CARS-3-1-11), and the 111 Project from the Ministry of Education of China (B07049).

\section{LITERATURE CITED}

1. Chen, W. Q., Wu, L. R., Xu, S. C., Jin, S. L., Peng, Y. L., and Wang, B. T. 2009. Race dynamics, diversity, and virulence evolution in Puccinia striiformis $\mathrm{f}$. sp. tritici, the causal agent of wheat stripe rust in China from 2003 to 2007. Plant Dis. 1093-1101.

2. Chen, X. M. 2005. Epidemiology and control of stripe rust on wheat. Can. J. Plant Pathol. 27:314-337.

3. Cummins, G. B., and Greene, H. C. 1966. A review of the grass rust fungi that have uredial paraphyses and aecia on Berberis-Mahonia. Mycologia 58:702-721.

4. Duan, X., Tellier, A., Wan, A., Leconte, M., de Vallavieille-Pope, C., and Enjalbert, J. 2010. Puccinia striiformis f. sp. tritici presents high diversity and recombination in the over-summering zone of Gansu, China. Mycologia 102:44-53.

5. Goddard, M. V. 1976. Cytological studies of Puccinia striiformis (yellow rust of wheat). Trans. Br. Mycol. Soc. 66:433-437.

6. Harder, D. E. 1984. Developmental ultrastructure of hyphae and spores. Pages 333-373 in: the Cereal Rusts, W. R. Bushnell, and A. P. Roelfs, eds. Academic Press, New York.

7. Jin, Y. 2011. Role of Berberis spp. as alternate hosts in generating new races of Puccinia graminis and P. striiformis. Euphytica 179:105-108.

8. Jin, Y., Szabo, L. J., and Carson, M. 2010. Century-old mystery of Puccinia striiformis life history solved with the identification of Berberis as an alternate host. Phytopathology 100:432-435.

9. Kang, Z. S., Li, Z. Q., and Shang, H. S. 1993. A new isolate produced by the heterokaryosis of wheat stripe rust. Acta Univ. Agric. BorealiOccident. 21:97-99. (In Chinese)

10. Kang, Z. S., Li, Z. Q., and Shang, H. S. 1994. Nuclear condition of uredinial stage of wheat stripe rust. Acta Phytopathol. Sin. 24:26-31. (In Chinese)

11. Kang, Z. S., Li, Z. Q., and Shang, H. S. 1994. On the screening of new heterokaryons of wheat stripe rust and its nuclear dissociation. Acta Phytopathol. Sin. 24:101-105. (In Chinese)

12. Kang, Z. S., Li, Z. Q., Shang, H. S., Lu, H. P., and Liu, X. D. 1994. Discovery of new isolates virulent to wheat cultivars of Mianyang system in wheat stripe rust. Acta Univ. Agric. Boreali-Occident. 22:7-11. (In Chinese) 
13. Kang, Z. S., Li, Z. Q., and Zhang, S. C. 1987. A preliminary study of pathogenic strain to Lovrin 13 of yellow rust of wheat. Acta Univ. Septentrionali Occident. Agric. 15:105-106. (In Chinese)

14. Li, Z. Q., and Zeng, S. M. 2002. Wheat Stripe Rust in China. China Agriculture Press, Beijing. (In Chinese)

15. Line, R. F., and Qayoum, A. 1992. Virulence, aggressiveness, evolution, and distribution of races of Puccinia striiformis (the cause of stripe rust of wheat) in North America, 1968-87. U.S. Dep. Agric. Tech. Bull. 1788.

16. Little, R., and Manners, J. G. 1969. Somatic recombination in yellow rust of wheat (Puccinia striiformis): I. The production and possible origin of two new physiologic races, Trans. Br. Mycol. Soc. 53:251-258.

17. Liu, M., and Hambleton, S. 2010. Taxonomic study of stripe rust, Puccinia striiformis sensu lato, based on molecular and morphological evidence. Fungal Biol. 114:881-899.

18. Lu, N. H., Zhan, G. M., Wang, J. F., Huang, L. L., and Kang, Z. S. 2009. Molecular evidence of somatic genetic recombination of Puccinia striiformis f. sp. tritici in China. Acta Phytopathol. Sin. 39:561-568. (In Chinese)

19. Ma, Q, Kang, Z. S., and Li, Z. Q. 1993.The fusion of urediospore germ tubes in Puccinia striiformis West. on wheat leaves. J. Northwest Sci.Tech. Univ. Agric. For. 21:97-98. (In Chinese)

20. Mboup, M., Leconte, M., Gautier, A., Wan, A. M., Chen, W., de Vallavieille-Pope, C., and Enjalbert, J. 2009. Evidence of genetic recombination in wheat yellow rust populations of a Chinese oversummering area. Fungal Genet. Biol. 46:299-307.

21. Payak, M. M. 1965. Berberis as the aecial host of Puccinia brachypodii in Simla Hills (India). J. Phytopathol. 52:49-54.

22. Qian, C. S., and Chen, H. Y. 2001. Flora of China. Pages 76-211 in: Berberidaceae, Vol. 29. J. S. Ying, ed. Science Press, Beijing. (In Chinese)

23. Rodenhiser, H. A., and Hard-Karrer, A. M. 1947. Evidence of fusion bodies from urediospore germ tubes of cereal rusts on nutrient-solution agar. Phytopathology 37:744-756.

24. Roelfs, A. P. 1982. Effects of barberry eradication on stem rust in the United States. Plant Dis. 66:177-181.

25. Shan, W. X., Chen, S. Y., and Kang, Z. S. 1998. Genetic diversity in Puccinia striiformis Westend. f. sp. tritici revealed by pathogen genomespecific repetitive sequence. Can. J. Bot. 76:587-595.
26. Stakman, E. C. 1919. The black stem rust and the barberry. Pages 75-100 in: U.S. Dep. Agriculture Yearb.

27. Stubbs, W. 1985. Stripe rust. Page 61-101 in: The Cereal Rusts, Vol. II. A. P. Roelfs, and W. R. Bushnell, eds. Academic Press, New York.

28. Urban, Z. 1967. The taxonomy of some European graminicolous rusts. Ceska Mykol. 21:12-16.

29. Wan, A. M., Zhao, Z. H., Chen, X. M., He, Z. H., Jin, S. L., Jia, Q. Z., Yao, G., Yang, J. X., Wang, B. T., Li, G. B., Bi, Y. Q., and Yuan, Z. Y. 2004. Wheat stripe rust epidemic and virulence of Puccinia striiformis $\mathrm{f}$. sp. tritici in China in 2002. Plant Dis. 88:896-904.

30. Wang, J. F., Chen, C. Q., Lu, N. H., Peng, Y. L., Zhan, G. M., Huang, L. L., and Kang, Z. S. 2010. SSR analysis of population genetic diversity of Puccinia striiformis f. sp. tritici in Sichuan Province, China. Mycosystema 29:206-213. (In Chinese)

31. Wang, K. N., Hong, X. W., Si, Q. M., Wang, J. X., and Shen, J. P. 1963. Studies of the physiology specialization of stripe rust of wheat in China. Acta Phytophylacia Sin. 2:23-36. (In Chinese)

32. Wu, L. R., Yang, H. A., Yuan, W. H., Song, W. Z., Yang, J. X., Li, Y. F., and $\mathrm{Bi}, \mathrm{Y}$. Q. 1993. On the physiological specialization of stripe rust of wheat in China during 1985-1990. Acta Phytopathol. Sin. 23:269-274. (In Chinese)

33. Zhan, G. M., Chen, X. M., Kang, Z. S., Huang, L. L., Wang, M. N., Wan, A. M., Cheng, P., Cao, S. Q., and Jin, S. L. 2012. Virulence and molecular comparison of Puccinia striiformis f. sp. tritici populations in China and the United States. Fungal Biol. 116:643-653.

34. Zhao, J., Wang, X. J., Chen, C. Q., Huang, L. L., and Kang, Z. S. 2007. A PCR-based assay for detection of Puccinia striiformis f. sp. tritici in wheat. Plant Dis. 91:1669-1674

35. Zhao, J., Zhang, H. C., Yao, J. N., Huang, L. L., and Kang, Z. S. 2011. Confirmation of Berberis spp. as alternate hosts of Puccinia striiformis $\mathrm{f}$. sp. tritici on what in China. Mycosystema 30:895-900. (In Chinese)

36. Zhao, L. S., and Wang, H. R. 1963. Primarily observation on fusion of germ tube urediospores of Puccinia striiformis f. sp. tritici. J. Agric. Univ. Hebei 2:1-6. (In Chinese)

37. Zheng, W. M., Chen, S. Y., Kang, Z. S., Wang, Y., Wu, L. R., and Li, Z. Q. 2005. DNA fingerprinting of natural population of Puccinia striiformis $\mathrm{f}$. sp. tritici in Tianshui area. Mycosystema 24:199-206. (In Chinese) 